\title{
ELECTRON SCATTERING ANISOTROPY IN SILICON
}

\author{
G. P. Gaidar ${ }^{1}$ (D) P. I. Baranskii ${ }^{2}$ \\ ${ }^{1}$ Institute for Nuclear Research of the NAS of Ukraine, \\ 47, Nauky Ave., Kyiv, UA-03028, Ukraine \\ e-mail: gaydar@kinr.kiev.ua \\ ${ }^{2} V$. Lashkaryov Institute of Semiconductor Physics of the NAS of Ukraine, \\ 45, Nauky Ave., Kyiv, UA-03028, Ukraine
}

(Received 05 July 2020; in final form 13 December 2020; accepted 21 December 2020; published online 03 March 2021)

\begin{abstract}
In $n$-Si single crystals, the scattering anisotropy of charge carriers has been studied depending on the compensation level of impurities. Theoretical calculations were carried out within the framework of the anisotropic scattering theory. The electrical conductivity, the Hall effect, and the tensoresistance of silicon crystals with various difference and summary concentrations of impurities were measured. It was established that an increase in the scattering anisotropy in $n$-Si crystals is practically independent of the degree of their compensation, but is associated only with an increase in the total concentration of ionized impurities. The intra-valley anisotropy of the scattering of charge carriers on dislocations as scatterers was studied for a fixed location of the current with respect to the direction of their preferred orientation. Dislocations (having a distinguished orientation) were introduced into the $n$-Si crystal by the plastic bending deformation at $1073 \mathrm{~K}$. It has been revealed that in $n$-Si crystals, the intra-valley anisotropy of the scattering on dislocations is much higher than the scattering anisotropy on the charged point defects.
\end{abstract}

Key words: silicon, Hall effect, tensoresistance, compensation degree, scattering anisotropy, dislocations.

DOI: https://doi.org/10.30970/jps.25.1602

\section{INTRODUCTION}

The volume and validity of the information available in the scientific literature on the specifics of the charge carrier scattering in $n$-Si are significantly lower than the level of knowledge of this issue for $n$-Ge [1-6]. Earlier, in our work [6], it was shown that the change in the scattering anisotropy under the influence of irradiation depends on the state of the oxygen impurity in germanium. It was established that scattering on electrically active (charged) oxygen complexes is less anisotropic than on ionized donors or acceptors of the usual type. A question arose whether and how much the level of compensation will affect the scattering anisotropy of charge carriers. The answer was obtained in this work when studying $n$-silicon single crystals.

It is known [7, 8] that dislocations (and especially orderly located dislocations) in crystals such as germanium and silicon are not only responsible for the appearance of deep centers, but to a large extent, if not completely, determine the mobility anisotropy of charge carriers and the anisotropy of other important characteristics of the corresponding crystals.

Dislocations in silicon are extended defects preserving the translational symmetry of the crystal lattice along its line, but breaking it in the transverse direction. Such defects have a significant effect on the mechanical and electrophysical properties of semiconductors, the kinetics of phase and structural transformations, diffusion processes, etc.

With the exception of internal gettering, for example, radiation defects in $\mathrm{Si}$ [9], semiconductor technology traditionally intends to avoid the formation of crystal defects like dislocations due to their harmful effects on the device performance. The dislocations, especially their clusters, are well known to reduce the minority charge carrier lifetime and hence the efficiency of solar cells [10]. Understanding the dislocation' roles results in the improvement of the crystal growth technique of high-performance Si cells by directional solidification from uniform small grains that relax thermal stress and suppress the massive generation and propagation of dislocation clusters [11].

With the development of new nanostructures on the basis of $\mathrm{Si}$, in the usage of dislocations as active components in semiconductor devices essentially increased. The development and implementation of the $\mathrm{Si}$ wafer direct bonding technique allows releasi$\mathrm{ng}$ the fabrication of the dislocation structure in a controlled manner and creating regular periodic dislocation networks [12]. In novel Si devices, dislocations can be used to develop (i) of a $1.5 \mu \mathrm{m} \mathrm{Si-based} \mathrm{light} \mathrm{emi-}$ tter for photonics compatible with CMOS technology; (ii) of the device based on the unusual transport of carriers along dislocations in $\mathrm{Si}$; (iii) of the device for the spatial control of the immobilization of biomolecules on the Si surface with a dislocation network [12].

The galvanomagnetic properties of semiconductors with orderly located dislocations should be anisotropic. The relevance of this is also increasing in connection with the development of a novel thermoelectric generator on the basis of $\mathrm{Si}$ nanostructures containing dislocation networks within a thin SOI (Silicon on Insulator) layer [12].

The aim of this work was to study the scattering anisotropy of electrons in $n$-silicon crystals: $a$ ) with different levels of compensation; $b$ ) at plastic bending deformation. 


\section{ELECTRON SCATTERING ANISOTROPY IN COMPENSATED $n$-SI CRYSTALS}

The scattering anisotropy of charge carriers was studied depending on the compensation level of impurities in $n$-Si crystals with a resistivity in the range of $23 \leq \rho_{300 \mathrm{~K}} \leq 1180 \mathrm{Ohm} \cdot \mathrm{cm}$. During the research, we used an installation that had been tested for many years [13], which made it possible to smoothly set it and remove the mechanical compressive stress in the range of $0 \leq X \leq 1.2 \mathrm{GPa}$ on the studied samples, which had the shape of parallelepipeds with dimensions $1 \times 1 \times 10 \mathrm{~mm}$. The uncertainty in determining the crystallographic orientation of the samples did not exceed $15^{\prime}$. Particular attention was paid to the fulfilment of the plane-parallelism of the opposite faces, in particular of the end sides of the sample, to which the load was applied, the deviation did not exceed $3^{\prime}$. The tensoresistance of the crystals was measured at $T=77 \mathrm{~K}$ using a current generator, which made it possible to carry out experiments with samples whose conductivity changed significantly. A stabilized direct current was applied to the end contacts, and the voltage drop was removed from ohmic contacts located along the sample, and the resistivity was determined from the value of this voltage. The contacts were deposited using the $\mathrm{Au}+\mathrm{Si}$ eutectic (unsaturated $\mathrm{Si}$ ) at the temperature of $723 \mathrm{~K}$, after which copper wires were soldered by tin to the created contacts. The contacts to the samples were tested for ohmicity at both room and nitrogen temperatures. To determine the mobility and the concentration of charge carriers (for samples cut from the same ingot of the test material), a typical Hall installation with an electromagnet was used. Differential preamplifiers were used to measure the potential difference on the electrical contacts of the test sample, whose output signal was input into a computer using an interface board with analog-to-digital converters for further processing and analysis.

The conductivity, the Hall effect, and the longitudinal tensoresistance were measured on the samples with a crystallographic orientation of [001] (under the conditions of $\mathbf{X}\|\mathbf{j}\|[001], 0 \leq X \leq 0.85 \mathrm{GPa}$ at $T=$ $77 \mathrm{~K}$, where $X$ is the mechanical compression stress, $j$ is the current through the sample). Theoretical calculations were carried out within the framework of the anisotropic scattering theory [14] using the NumPy, SciPy, and MpMath libraries of the Python software package.

The electron mobility in silicon, according to the formulas of the anisotropic scattering theory, is completely determined by the tensors of the effective mass and relaxation time. When taking into account the intra-valley, intervalley, and impurity scattering, the components of the relaxation time tensor have the following form:

$$
\begin{aligned}
& \tau_{\|}=\frac{a_{\|}}{T \sqrt{k T}} \frac{x^{3 / 2}}{x^{2}+\frac{2}{3} \varphi x^{3 / 2}+b_{0}} \\
& \tau_{\perp}=\frac{a_{\perp}}{T \sqrt{k T}} \frac{x^{3 / 2}}{x^{2}+\varphi x^{3 / 2}+b_{1}}
\end{aligned}
$$

where $k$ is the Boltzmann constant; $T$ is the temperature; the $\varphi(x, T)$ function is defined in the Appendix by the expression (A.8); the $b_{0}$ and $b_{1}$ values are defined by the expressions (A.9); $a_{\|}$and $a_{\perp}$ are the numerical coefficients, which for $n$-Si under the mixed scattering conditions are (according to (A.13)) $a_{\|}=3.09 \times 10^{-17}$, $a_{\perp}=4.67 \times 10^{-17} \mathrm{erg}^{1 / 2} \cdot \mathrm{K} \cdot \mathrm{s}$.

Fig. 1 shows the theoretical dependences of the Hall mobility $\mu_{\mathrm{H}}$ and the Hall factor $r=\mu_{\mathrm{H}} / \mu(\mu$ is the drift mobility of charge carriers) on the concentration of ionized $N_{\mathrm{i}}$ impurities in $n$-Si at $T=77 \mathrm{~K}$. This temperature corresponds to the complete ionization of impurities $\left(10^{12} \leq N_{\mathrm{i}} \leq 10^{16} \mathrm{~cm}^{-3}\right)$ contained in the bulk of $n$-Si crystals. Dependences were calculated for the case of non-degenerate statistics according to the (A.1)-(A.3) formulas of Appendix using the integrals (A.6) and (A.7) [15].

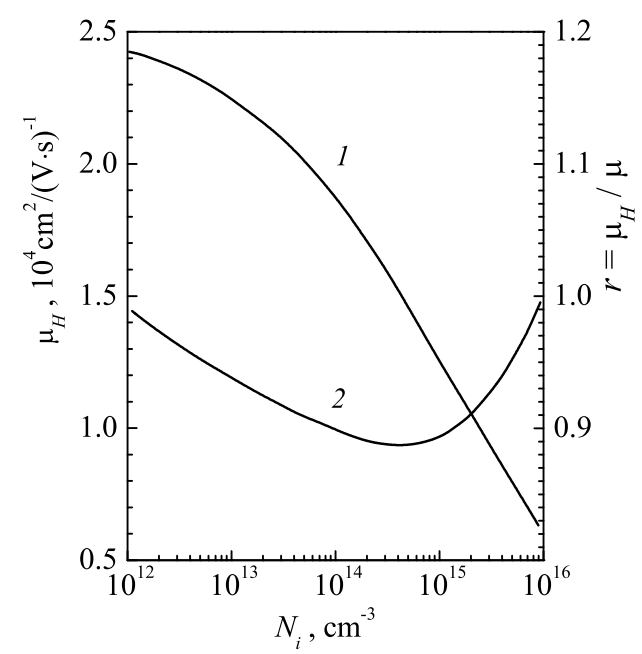

Fig. 1. Dependences of the Hall mobility $\mu_{\mathrm{H}}(1)$ and the Hall factor $r$ (2) on the concentration of ionized $N_{\mathrm{i}}$ impurities in $n$-Si at $T=77 \mathrm{~K}$

The measurements of the electrical conductivity and the Hall effect, as well as the use of the theoretical dependences $\mu_{\mathrm{H}}=\mu_{\mathrm{H}}\left(N_{\mathrm{i}}\right)$ and $r=\mu_{\mathrm{H}} / \mu=f\left(N_{\mathrm{i}}\right)$ (Fig. 1), provided the information about the concentrations of donors $N_{\mathrm{d}}$ and acceptors $N_{\mathrm{a}}$, and also about the total concentration of ionized impurities $N_{\mathrm{i}}=N_{\mathrm{d}}+N_{\mathrm{a}}$ and the compensation degree of impurities $k=N_{\mathrm{a}} / N_{\mathrm{d}}$ in the studied silicon samples (Table 1 ). The experimental results on tensoresistance (Fig. 2) together with expression [16]

$$
K=\frac{3}{2} \frac{\rho_{\infty}^{[001]}}{\rho_{0}}-\frac{1}{2}
$$

provided the information about the mobility anisotropy parameter for $n$-Si.

$$
K \equiv K_{\text {exper }}=\frac{K_{m}}{K_{\tau}}=\frac{m_{\|}}{m_{\perp}} \frac{\left\langle\tau_{\perp}\right\rangle}{\left\langle\tau_{\|}\right\rangle}=\frac{\mu_{\perp}}{\mu_{\|}},
$$


where $\rho_{0}(X=0)$ and $\rho_{\infty}=\lim _{X \rightarrow \infty} \rho(X)$ are the resistivity of the undeformed (at $X=0$ ) sample and at $X \rightarrow \infty$ (i.e., $\rho=\rho(X)$ in the saturation region); $K_{m}$ is the anisotropy parameter of the effective mass (in the case of $n$-Si at $T=77 \mathrm{~K}$ the value $K_{m}=m_{\|} / m_{\perp} \approx$ $0.916 m_{0} / 0.199 m_{0} \approx 4.61=$ const is accepted); $m_{\|}$ and $m_{\perp}$ are the cyclotron effective masses for a single isoenergetic ellipsoid along the long axis and across it, respectively; $K_{\tau}=\left\langle\tau_{\|}\right\rangle /\left\langle\tau_{\perp}\right\rangle$ is the scattering anisotropy parameter; $\tau_{\|}$and $\tau_{\perp}$ are the components of the relaxation time tensor in the absence of a magnetic field in the linear approximation; $K=\mu_{\perp} / \mu_{\|}$is the mobility anisotropy parameter (the ratio of the mobilities $\mu_{\perp}$ and $\mu_{\|}$ along the main axes of the tensor of masses for electrons of one valley).

\begin{tabular}{ccccccccccc}
\hline Sample & $\rho_{300 \mathrm{~K}}$, & \multicolumn{10}{c}{$T=77 \mathrm{~K}$} \\
\cline { 3 - 11 } number & Ohm $\cdot \mathrm{cm}$ & $\begin{array}{c}\mu_{\mathrm{H}}, \\
\mathrm{cm}^{2}\end{array}$ & $\begin{array}{c}N_{\mathrm{i}}, 10^{13} \\
\mathrm{~cm}^{-3}\end{array}$ & $\begin{array}{c}n_{e}, 10^{13} \\
\mathrm{~cm}^{-3}\end{array}$ & $\begin{array}{c}N_{\mathrm{d}}, 10^{13} \\
\mathrm{~cm}^{-3}\end{array}$ & $\begin{array}{c}N_{\mathrm{a}}, 10^{13} \\
\mathrm{~cm}^{-3}\end{array}$ & $k$ & $K_{\text {exper }}$ & $K_{\tau}$ & $\frac{\rho_{X(\infty)}}{\rho_{0}}$ \\
\hline 1 & 1180 & 20700 & 3.63 & 0.33 & 1.98 & 1.65 & 0.833 & 6.33 & 0.728 & 4.55 \\
2 & 102 & 19600 & 6.77 & 4.09 & 5.43 & 1.34 & 0.247 & 6.16 & 0.748 & 4.43 \\
3 & 66 & 16900 & 21.6 & 5.80 & 13.7 & 7.90 & 0.577 & 5.20 & 0.885 & 3.80 \\
4 & 23 & 16250 & 27.6 & 17.0 & 22.3 & 5.30 & 0.238 & 5.04 & 0.915 & 3.69 \\
\hline
\end{tabular}

Table 1. The compensation degree $k$ and the connection between the scattering anisotropy $K_{\tau}$ and the total content of ionized $N_{\mathrm{i}}$ impurities in the studied $n$-Si crystals

The compensation degree $k=N_{\mathrm{a}} / N_{\mathrm{d}}$ of the samples was obtained as follows. Having experimentally determined the value of Hall mobility, the corresponding concentration of ionized $N_{\mathrm{i}}$ impurities was found from curve 1 (Fig. 1), and the Hall factor $r$ corresponding to this $N_{\mathrm{i}}$ value was found from curve 2. Knowing the magnitude of the Hall factor, we can calculate the concentration of conduction electrons from the experimental values of the Hall coefficient $R_{\mathrm{H}}$ according to the formula

$$
n_{e}=\frac{r\left(N_{\mathrm{i}}\right)}{c e R_{\mathrm{H}}}
$$

where $e$ is the electron charge; $c=3 \times 10^{8} \mathrm{~m} / \mathrm{s}$ is the electrodynamic constant.

Having the values of $N_{\mathrm{i}}$ and $n_{e}$, which under the experiment conditions are the total and difference concentrations of impurities contained in the crystal volume,

$$
\begin{aligned}
& N_{\mathrm{i}}=N_{\mathrm{d}}+N_{\mathrm{a}}, \\
& n_{e}=N_{\mathrm{d}}-N_{\mathrm{a}},
\end{aligned}
$$

and having solved the system of equations (5) and (6), we obtain the desired compensation degree of impurities in the crystal in the form of the ratio:

$$
k=\frac{N_{\mathrm{a}}}{N_{\mathrm{d}}}=\frac{N_{\mathrm{i}}-n_{e}}{N_{\mathrm{i}}+n_{e}} .
$$

It should be noted that, since the presence of a concentration gradient of impurities substantially affects the value of the Hall mobility, the samples under study should be uniform enough. To satisfy this requirement, the samples were cut along the lines of the same resistivity, which are detected using the anodic etching method, that is, almost perpendicular to the growth axis of the studied single crystals. In this case, the effect of concentration gradients on the effective mobility will be minimal.

The detailed characteristics of $n$-Si samples and the main results are presented in Table 1 .

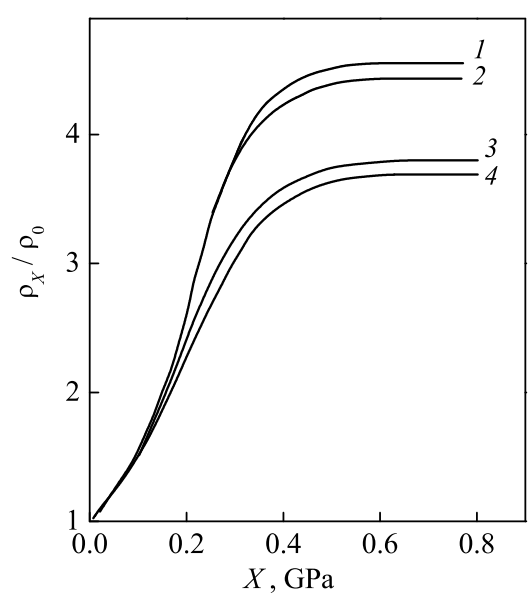

Fig. 2. Dependences $\rho_{X} / \rho_{0}=f(X)$ under the conditions $\mathbf{X}\|\mathbf{j}\|[001]$ at $T=77 \mathrm{~K}$ for $n$-Si samples with the characteristics given in Table 1 . The numbers of the curves correspond to the numbers of the samples

The data in Fig. 2 and Table 1 allow us to conclude that both in the transition from curves 1, 2 to curves 3 , 4, and in the transitions $1 \rightarrow 2$ or $3 \rightarrow 4$, the decrease in the values of tensoresistance in saturation $\rho_{\infty} / \rho_{0}$ (and, consequently, the mobility anisotropy parameter $\left.K=K_{m} / K_{\tau}\right)$ is directly linked to the increase in the total amount of impurity ions $N_{\mathrm{d}}+N_{\mathrm{a}}=N_{\mathrm{i}}$ and practi- 
cally does not depend on the degree of their compensation. For this reason, the value of the anisotropy parameter $K_{\text {exper }}=6.33$ (found in the experiments on tensoresistance with sample 1 (Fig. 2) using expression (2)) can be identified with the value of this parameter that would be obtained (with the same value of the concentration of the dopant impurities $N=N_{\mathrm{i}}=3.63 \times 10^{13} \mathrm{~cm}^{-3}$ ) in the absence of compensation. But the value of $K$ precisely for this case (i.e., for an uncompensated crystal), taking into account the intra-valley and intervalley scattering, can be obtained theoretically and the result can be compared with experiment.

Indeed, using (3) and the expressions for the components of the relaxation time tensor at the scattering on phonons, taking into account the intra-valley and intervalley scattering,

$$
\tau_{\|}=\frac{a_{\perp}}{T \sqrt{k T}} \frac{1}{\sqrt{x}+\frac{2}{3} \varphi}, \quad \tau_{\perp}=\frac{a_{\perp}}{T \sqrt{k T}} \frac{1}{\sqrt{x}+\varphi},
$$

we then obtain

$$
\begin{gathered}
K_{\tau}=\frac{\left\langle\tau_{\|}\right\rangle}{\left\langle\tau_{\perp}\right\rangle}=\frac{a_{\|}}{a_{\perp}} \frac{J_{1}}{J_{2}}, \\
K=\frac{K_{m}}{K_{\tau}}=K_{m} \frac{a_{\perp}}{a_{\|}} \frac{J_{2}}{J_{1}},
\end{gathered}
$$

where, according to (A.12) from the Appendix, $a_{\|}=$ $3.50 \times 10^{-17}, a_{\perp}=5.25 \times 10^{-17} \mathrm{erg}^{1 / 2} \cdot \mathrm{K} \cdot \mathrm{s} ; K_{m} \approx 4.61$. Substituting the numerical values of the parameters in (8), and also calculating the integrals $J_{1}$ and $J_{2}$ given in the Appendix by formulas (A.4), (A.8), we obtain (for $T=77 \mathrm{~K}) K=6.72$. If we take into account not only the scattering on phonons, but also the scattering on impurities $\left(N_{\mathrm{i}}=3.63 \times 10^{13} \mathrm{~cm}^{-3}, J_{1} \rightarrow J_{1}^{\prime}, J_{2} \rightarrow J_{2}^{\prime}\right.$, according to formulas (A.6), (A.8), (A.9) and (A.13)), then we obtain the value of the parameter $K=6.26$, which is in good agreement with the experimentally found value of $K_{\text {exper }}=6.33$.

Thus, the study of the tensoresistance of $n$-Si crystals, having various difference and summary impurity concentration, showed that the compensation (at least for $k=N_{\mathrm{a}} / N_{\mathrm{d}} \leq 0.83$ and for $N_{\mathrm{i}} \equiv N_{\mathrm{d}}+N_{\mathrm{a}} \leq 2.76 \times$ $10^{14} \mathrm{~cm}^{-3}$ ) practically does not change the scattering anisotropy of charge carriers. The observed changes in the scattering anisotropy are associated only with the change in the contribution of the impurity scattering.

\section{ELECTRON SCATTERING ANISOTROPY IN SILICON UNDER PLASTIC BENDING DEFORMATION}

The intra-valley anisotropy of the scattering of charge carriers $K_{\tau}=\left\langle\tau_{\|}\right\rangle /\left\langle\tau_{\perp}\right\rangle$ on the dislocations as scatterers was studied for a fixed location of the current $\mathbf{j}$ relative to the direction of their preferred orientation. To introduce dislocations into $n$-Si single crystals, plastic deformation of the samples was used. After the chemical polishing of silicon, a scratch was applied with a diamond needle (indenter), which served as a stress concentrator for the generation of dislocations in the process of subsequent plastic deformation. Dislocations with a density of $N_{\mathrm{D}}$ (having the highlighted orientation) were introduced into $n$-Si crystal $\left(\rho_{300 \mathrm{~K}}=100 \mathrm{Ohm} \cdot \mathrm{cm}\right.$; $\left.N_{\text {Dinitial }}=10^{3} \mathrm{~cm}^{-2}\right)$ by plastic bending deformation at the temperature of $1073 \mathrm{~K}$ in a ceramic furnace (Fig. 3, scheme in the inset). After the deformation process was completed, the load was removed from the sample, and it was cooled together with the furnace. The angle between the current $\mathbf{j}$ and the dislocations introduced through the plastic deformation in the experiments was about $90^{\circ}$. The studied samples had sizes of $1 \times 1 \times 10 \mathrm{~mm}$.

The dislocation density was determined by etching pits on the (111) plane of silicon crystals after treatment in a selective etchant $2 \mathrm{HNO}_{3}+\mathrm{HF}+\mathrm{CH}_{3} \mathrm{COOH}$. The first component (nitric acid) oxidized the surface of the sample, the second (hydrofluoric acid) made it soluble, and the third component (acetic acid) served as a buffer that controls the reaction rate.

It should be noted that the result of etching the surface of the sample substantially depends on its crystallographic orientation. Tightly packed planes are generally easier to etch. For single-crystal silicon, these are (111) or (110) types of planes. The shape of the etched figures is also determined by the type of the crystallographic plane.

When a defect-free surface of a semiconductor is etched, it remains flat and clean. Defective areas are etched differently to form pits or hillocks. Stacking faults, some inclusions, and small dislocation loops are etched in the form of flat pits in silicon. Dislocations are etched in the form of pits with a peak, which deepen with an increase in the etching duration without changing its shape and morphology. If a dislocation is not perpendicular to the surface, the shape of the pit will be irregular. At the beginning of etching, linear and localized defects can be of the same morphology, but with an increase in the etching duration, the former retain their shape, and the latter reveal their flat bottom. During the repeated etching of the crystal the etching pits, associated with dislocations, appear in the same places as previously revealed. In this way, dislocations that cross the surface of the sample can be detected.

We obtain the scattering anisotropy parameter $K_{\tau}$ from expression (3):

$$
K_{\tau}=\frac{\left\langle\tau_{\|}\right\rangle}{\left\langle\tau_{\perp}\right\rangle}=\frac{K_{m}}{K} .
$$

The value of the mobility anisotropy parameter $K$ for $n$-Si can be found from the tensoresistance obtained in experiments with crystals subjected to (after their plastic deformation) uniaxial elastic deformation under the conditions $\mathbf{X}\|\mathbf{j}\|[001], 0 \leq X \leq 0.8 \mathrm{GPa}$ at $T=77 \mathrm{~K}$, from expression (2). Herewith in the absence of saturation of the function $\rho_{X} / \rho_{0}=f(X)$, which is typical of samples with the highest dislocation densities $N_{\mathrm{D}}$ (Fig. 3, curves 8,9 ), the values of this ratio in the maximum of the function $\rho_{X} / \rho_{0}=f(X)$ were taken as $\rho_{\infty} / \rho_{0}$. 
It should be noted that in the general case, in the samples with a high density of the oriented dislocations, the mobility $\mu_{\perp}$ in the longitudinal and transverse directions relative to the direction of the dislocations can differ significantly. But since in the case under consideration there are two groups of dislocations in the (001) plane, intersecting at the right angle, then the anisotropy $\mu_{\perp}$ in the (001) plane does not lead to differences in mobility that go beyond the experiment error.

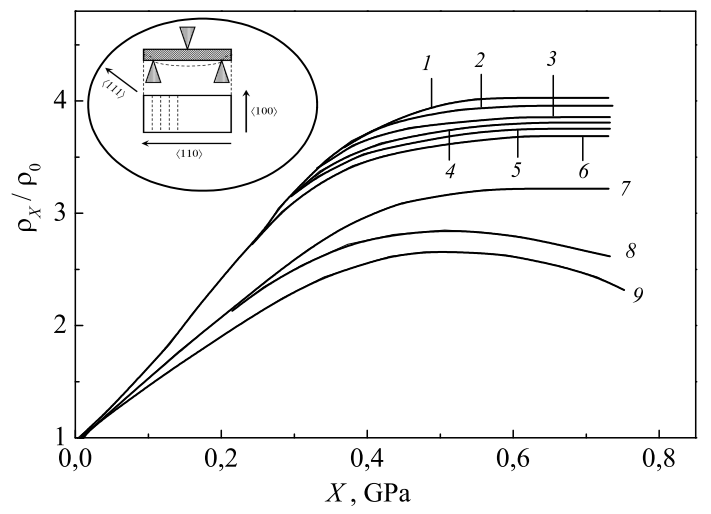

Fig. 3. Dependences of tensoresistance of $n$-Si samples on the value of the mechanical compression $(\mathbf{X}\|\mathbf{j}\|$ [001], $T=$ $77 \mathrm{~K}): 1$ - initial sample; 2 - annealed at $1073 \mathrm{~K}$ for $2 \mathrm{~h}$; $3-9$ - samples with introduced dislocations with a density of $N_{\mathrm{D}}, \mathrm{cm}^{-2}: 3-3 \times 10^{5}, 4-6 \times 10^{5}, 5-2 \times 10^{6}, 6-$ $5 \times 10^{6}, 7-5 \times 10^{7}, 8-5 \times 10^{8}, 9-10^{9}$. The inset shows the scheme for introducing dislocations using the method of plastic bending deformation at $T=1073 \mathrm{~K}$

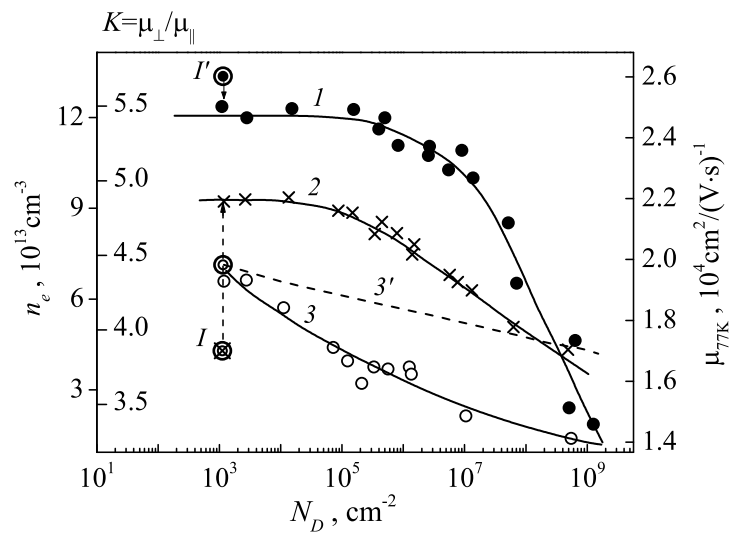

Fig. 4. For $n$-Si samples, dependences on the dislocation density $N_{\mathrm{D}}$ : $1-$ mobility anisotropy parameter $K=K_{m} / K_{\tau}$; 2 - charge carrier concentration $n_{e} ; 3$ - their mobilities $\mu$ at $T=77 \mathrm{~K}$. Curve $3^{\prime}$ is the dependence $\mu=\mu\left(N_{\mathrm{i}}\right)$ $\left(1.43 \times 10^{14} \leq N_{\mathrm{i}} \leq 2.17 \times 10^{14} \mathrm{~cm}^{-3}\right)$ calculated using the formulas of the anisotropic scattering theory, taking into account the intra-valley, intervalley and impurity scattering

The dependences $K\left(N_{\mathrm{D}}\right), n_{e}\left(N_{\mathrm{D}}\right)$, and $\mu_{77 \mathrm{~K}}\left(N_{\mathrm{D}}\right)$ for $n$-Si samples obtained on the basis of the data in Fig. 3 was displayed in Fig. 4 (curves 1-3).

It should be noted that the parameter $K$ characterizes the mobility anisotropy electrons belonging to one valley (the total mobility of electrons in silicon crystals is isotropic due to the cubic symmetry of these crystals and the high symmetry in the arrangement of isoenergetic ellipsoids with respect to the crystallographic axes). The mobility anisotropy parameter $K$ is included in the expressions for all kinetic coefficients without exception and, therefore, is of great importance for any of the kinetic effects.

Within framework of the anisotropic scattering theory for $n$-Si crystals under mixed scattering conditions (taking into account the intra-valley, intervalley, and impurity scattering), the mobility anisotropy parameter can be written in the form of expression (10). However, in this case it is necessary to use the coefficients $a_{\|}$and $a_{\perp}$ from the Appendix (A.13); and to use the integrals $J_{1}^{\prime}$ and $J_{2}^{\prime}$ (A.6) instead of the integrals $J_{1}$ and $J_{2}$ taking into account the formulas (A.8) and (A.9).

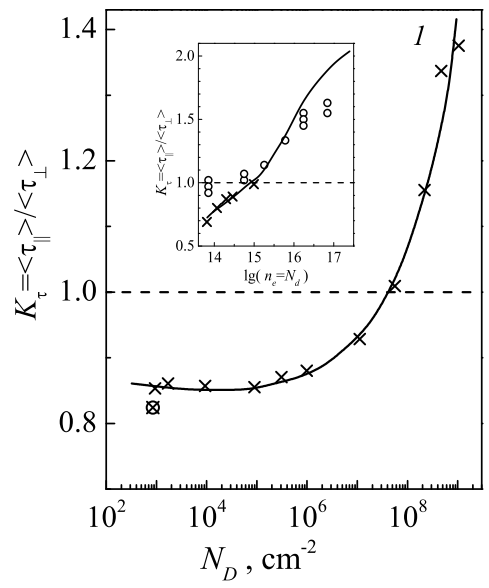

Fig. 5. For $n$-Si samples: 1 - dependence of the scattering anisotropy parameter $K_{\tau}$ on the dislocation density at $77 \mathrm{~K}$. The inset shows the $K_{\tau}$ dependence on the concentration of donor impurity in $n$-Si at $77 \mathrm{~K}$ : solid line is the theoretical calculation; $\circ, \times-$ the experimental results from [15]

Plastic deformation of $n$-Si at elevated temperatures introduces point defects of the donor and acceptor type (along with dislocations) into the volume of the deformable crystal. Having the $n_{e}=N_{\mathrm{d}}-N_{\mathrm{a}}$ values for the sample in the initial state (with a relatively low density of growth dislocations $N_{\text {D initial }}$ ) (Fig. 4, point $I$ ), as well as the $K$ value for the sample in the same state (Fig. 4, point $I^{\prime}$ ), based on the relation (11) and the existing connection between $K_{\tau}$ and $n_{e} \equiv N_{\mathrm{d}}=N_{\mathrm{i}}$ in the form of

$$
K_{\tau}=\frac{\left\langle\tau_{\|}\right\rangle}{\left\langle\tau_{\perp}\right\rangle}=\frac{a_{\|}}{a_{\perp}} \frac{J_{1}^{\prime}}{J_{2}^{\prime}},
$$

(where, according to (A.13) from the Appendix, $a_{\|}=$ $3.09 \times 10^{-17}, a_{\perp}=4.67 \times 10^{-17} \mathrm{erg}^{1 / 2} \cdot \mathrm{K} \cdot \mathrm{s} ; J_{1}^{\prime}$ and $J_{2}^{\prime}$ are the integrals (A.6)), one can find the summary value of the ionized impurities $N_{\mathrm{i}}^{0}=N_{\mathrm{d}}+N_{\mathrm{a}}$, characteristic of the same sample in the initial state. Based on the results of $[17,18]$, it can be assumed that annealing leads practically only to the generation of donors, and the introduction of dislocations at high-temperatures (1023-1073 K) 
plastic deformation leads to the generation of acceptors, according to $[7,19]$. Thus, taking into account $N_{\mathrm{i}}^{0}$, as well as the values of $n_{e}$, represented by curve 2 in Fig. 4 (assuming that annealing leads only to the generation of donors, and the introduction of dislocations leads to the generation of acceptors), we can find the summary concentration of $N_{\mathrm{i}}$ for a sample with any $N_{\mathrm{D}}$ content. For a sample with the concentration $N_{\mathrm{D}}=5 \times 10^{7} \mathrm{~cm}^{-2}$, in which the $K_{\tau}$ transition through the unit is observed (due to point defects) in curve 1 (Fig. 5 ), $N_{\text {i }}$ turns out to be $1.79 \times 10^{14} \mathrm{~cm}^{-3}$. On the other hand, from the data in the inset (Fig. 5), borrowed from [15], it follows that a similar $K_{\tau}$ transition through the unit due to point defects alone can be realized at $N_{\mathrm{i}}>10^{15} \mathrm{~cm}^{-3}$. It follows from this that the intra-valley anisotropy of scattering by dislocations is much higher than the anisotropy of scatter- ing by charged point defects.

Assuming that the acceptor centers arising at plastic deformation are also point defects, using the values of $1.43 \times 10^{14} \leq N_{\mathrm{i}} \leq 2.17 \times 10^{14} \mathrm{~cm}^{-3}$, found for all the samples studied, we can calculate using the formulas of anisotropic scattering theory (A.2), (A.6)-(A.9), given in the Appendix, the dependence $\mu=\mu\left(N_{\mathrm{i}}\right)$ taking into account the intra-valley, intervalley and impurity scattering. The results of these calculations, presented in the form of curve $3^{\prime}$ (Fig. 4), are compared with the experimentally found mobility values determined by scattering on the point defects and dislocations (Fig. 4, curve 3). It was shown that (in comparison with point scattering centers) the dislocations are characterized not only by a more essential scattering anisotropy, but also an increased level of its overall efficiency.

\begin{tabular}{lcccccc}
\hline State of sample & $\begin{array}{c}T_{\text {exper }}, \\
\mathrm{K}\end{array}$ & $n_{e}, 10^{13}$ & $\gamma=\frac{n_{e}(300 \mathrm{~K})}{n_{e}(77 \mathrm{~K})}$ & $\begin{array}{c}\mu_{e}, \\
\mathrm{~cm}^{2} /(\mathrm{V} \cdot \mathrm{s})\end{array}$ & $\frac{\mu_{e}(77 \mathrm{~K})}{\mu_{e}(300 \mathrm{~K})}$ & $K_{\tau}$ \\
\hline Initial sample & 300 & 5.90 & 1.36 & $\begin{array}{c}1800 \\
19750\end{array}$ & 15.8 & $\begin{array}{c}- \\
0.832\end{array}$ \\
\hline After initial sample & 300 & 10.3 & 1.10 & 1900 & 14.8 & - \\
heating $(1073 \mathrm{~K}, 2 \mathrm{~h})$ & 77 & 9.35 & & 19171 & & 0.855 \\
\hline After deformation to & 300 & 14.0 & 2.19 & 1300 & 11.55 & - \\
$N_{\mathrm{D}}=10^{7} \mathrm{~cm}^{-2}$ & 77 & 6.4 & & 15000 & & 0.932 \\
\hline After deformation to & 300 & 21.8 & 4.53 & 1250 & 11.2 & - \\
$N_{\mathrm{D}}=5 \times 10^{8} \mathrm{~cm}^{-2}$ & 77 & 4.8 & & 14000 & & 1.344 \\
\hline
\end{tabular}

Table 2. Change in the main parameters of $n$-Si samples as a result of their plastic deformation

The increase in the coefficient $\gamma=$ $n_{e}(300 \mathrm{~K}) / n_{e}(77 \mathrm{~K})$ (Table 2$)$ observed in this work is explained by an increase in the role of the deep donor level $(\sim 0.4 \mathrm{eV})$ associated with the localization of defects or their complexes near the introduced dislocations [20]. It should be noted that with an increase in $N_{\mathrm{D}}$, not only an increase in the gap $\Delta E_{1}$ between the bottom of the conduction band (c-band) and the position of the main deep donor level is observed. There is also a change in the magnitude of $\Delta E_{1}$ (decrease) with an increase in the mechanical stress $\mathbf{X} \|$ [001] (at least at the highest dislocation densities $N_{\mathrm{D}}$ ), which is manifested in a decrease in $\rho_{X} / \rho_{0}$ (due to an increase in $n_{e}$ in the $c$-band) after the maximum (see Fig. 3, curves 8,9$)$.

\section{CONCLUSIONS}

1. It was established that the increase in the $K_{\tau}$ scattering anisotropy in compensated $n$-Si crystals is practically independent of the degree of their compensation (at least for $k=N_{\mathrm{a}} / N_{\mathrm{d}} \leq 0.83$ and for $N_{\mathrm{i}} \equiv N_{\mathrm{d}}+N_{\mathrm{a}} \leq 2.76 \times 10^{14} \mathrm{~cm}^{-3}$ ), but is associated with an increase in the total concentration of ionized $N_{\mathrm{i}}$ impurities.
2. It was revealed that in $n$-Si crystals, the intravalley anisotropy of scattering on the dislocations introduced through the plastic bending deformation at $1073 \mathrm{~K}$ is significantly higher than the scattering anisotropy on charged point defects.

3. By comparing experimentally found values of the charge carrier mobility, which are determined by the scattering on point defects and dislocations, with the results of calculations within the framework of the theory of anisotropic scattering it was shown, that the dislocations in $n$-Si (as compared with point scattering centers) are characterized not only by a more essential scattering anisotropy, but also an increased level of its overall effectiveness.

4. It was found that plastic deformation of $n$-Si crystals not only causes an increase in the $\Delta E_{1}$ gap between the bottom of the $c$-band and the position of donor centers, but also leads to a decrease $\Delta E_{1}$ at the highest dislocation densities $N_{\mathrm{D}}=$ $5 \times 10^{8}-1 \times 10^{9} \mathrm{~cm}^{-2}$ with an increase in the mechanical compression stress. 


\section{APPENDIX}

The Appendix contains formulas for calculating the drift $\mu$ and Hall $\mu_{\mathrm{H}}$ mobilities of charge carriers, as well as the Hall factor $r$ in $n$-Si (within the framework of the anisotropic scattering theory):

$$
\begin{gathered}
\mu=1.456 \frac{10^{6}}{T^{3 / 2}}\left(J_{1}+14.06 J_{2}\right) \mathrm{cm}^{2} /(\mathrm{V} \cdot \mathrm{s}), \\
\mu_{\mathrm{H}}=3.51 \frac{10^{7}}{T^{3 / 2}} \frac{6.95 J_{4}+2 J_{3}}{J_{1}+13.9 J_{2}} \mathrm{~cm}^{2} /(\mathrm{V} \cdot \mathrm{s}), \\
r=\frac{\mu_{\mathrm{H}}}{\mu}=27.7 \frac{2 J_{3}+6.95 J_{4}}{\left(J_{1}+13.9 J_{2}\right)^{2}}
\end{gathered}
$$

where $J_{1}, J_{2}, J_{3}, J_{4}$ are the kinetic integrals.

For the scattering of charge carriers on phonons (taking into account the intra-valley and intervalley scattering), the integrals $J_{1}-J_{4}$ have the form:

$$
\begin{gathered}
J_{1}=\int_{0}^{\infty} \frac{e^{-x} x^{3 / 2}}{\sqrt{x}+\frac{2}{3} \varphi} d x, \quad J_{2}=\int_{0}^{\infty} \frac{e^{-x} x^{3 / 2}}{\sqrt{x}+\varphi} d x, \\
J_{3}=\int_{0}^{\infty} \frac{e^{-x} x^{3 / 2}}{\left(\sqrt{x}+\frac{2}{3} \varphi\right)(\sqrt{x}+\varphi)} d x, \quad J_{4}=\int_{0}^{\infty} \frac{e^{-x} x^{3 / 2}}{(\sqrt{x}+\varphi)^{2}} d x .
\end{gathered}
$$

In the case of the mixed scattering of charge carriers (taking into account the intra-valley, intervalley, and impurity scattering) in formulas (A.1)-(A.3), instead of the $J_{1}-J_{4}$ integrals, one should use the integrals $J_{1}^{\prime}-J_{4}^{\prime}$ :

$$
\begin{gathered}
J_{1}^{\prime}=\int_{0}^{\infty} \frac{e^{-x} x^{3}}{x^{2}+\frac{2}{3} x^{3 / 2} \varphi+b_{0}} d x, J_{2}^{\prime}=\int_{0}^{\infty} \frac{e^{-x} x^{3}}{x^{2}+x^{3 / 2} \varphi+b_{1}} d x, \\
J_{3}^{\prime}=\int_{0}^{\infty} \frac{e^{-x} x^{9 / 2}}{\left(x^{2}+\frac{2}{3} x^{3 / 2} \varphi+b_{0}\right)\left(x^{2}+x^{3 / 2} \varphi+b_{1}\right)} d x, J_{4}^{\prime}=\int_{0}^{\infty} \frac{e^{-x} x^{9 / 2}}{\left(x^{2}+x^{3 / 2} \varphi+b_{1}\right)^{2}} d x .
\end{gathered}
$$

The function $\varphi(x, T)$ has the form:

$$
\begin{aligned}
\varphi(x, T) & =\frac{28.5}{e^{190 / T}-1}\left[\sqrt{x+\frac{190}{T}}+e^{190 / T} \theta\left(x, \frac{190}{T}\right) \sqrt{x-\frac{190}{T}}\right] \\
& +\frac{1260}{e^{630 / T}-1}\left[\sqrt{x+\frac{630}{T}}+e^{630 / T} \theta\left(x, \frac{630}{T}\right) \sqrt{x-\frac{630}{T}}\right],
\end{aligned}
$$

and $\theta(x, a)= \begin{cases}1 & \text { for } x>a \\ 0 & \text { for } x<a\end{cases}$

The values $b_{0}$ and $b_{1}$, which are part of the integrals $J_{1}^{\prime}-J_{4}^{\prime}$, depending on the concentration and temperature, for $n$-Si in the case of non-degenerate statistics can be written as:

$$
\left\{\begin{array}{l}
b_{0}=2.99 \times 10^{-11} \frac{N}{T^{3}}\left(32.0+\ln \frac{T^{2} x}{N}+10^{-14} \frac{N}{T^{2} x}\right) \\
b_{1}=1.62 \times 10^{-10} \frac{N}{T^{3}}\left(31.4+\ln \frac{T^{2} x}{N}+1.46 \times 10^{-14} \frac{N}{T^{2} x}\right),
\end{array}\right.
$$

where $N=N_{\mathrm{d}}+N_{\mathrm{a}}$ is the total concentration of ionized impurities. 
Kinetic integrals were calculated using quadrature formulas of the highest degree of accuracy:

$$
J_{n}^{\prime}=\int_{0}^{\infty} x^{s} e^{-x} f(x) d x \approx \sum_{k=1}^{n} A_{k} f\left(x_{k}\right),
$$

where the weighting multipliers $A_{k}$ and the nodal points $x_{k}$ depend on the number of nodes $n$, and also on the form of the "weighting" Laguerre function $x^{s} e^{-x}$. The optimal or eigenvalue $s$ will be such that the function is the smoothest in the main integration area. The formula for calculating the mobility anisotropy parameter is:

$$
K=\frac{K_{m}}{K_{\tau}}=K_{m} \frac{a_{\perp}}{a_{\|}} \frac{J_{2}}{J_{1}},
$$

where $K_{m}=m_{\|} / m_{\perp} \approx 0.916 m_{0} / 0.199 m_{0} \approx 4.61$ is the anisotropy parameter of the effective mass for $n$-Si at $T=77 \mathrm{~K} ; K_{\tau}=\left\langle\tau_{\|}\right\rangle /\left\langle\tau_{\perp}\right\rangle$ is the scattering anisotropy parameter; $a_{\|}$and $a_{\perp}$ are the numerical coefficients that depend only on the values of the effective masses of the electron, the elastic constants and the constants of the deformation potential. For $n$-Si, the integrals $J_{1}, J_{2}$ and the coefficients

$$
\begin{aligned}
& a_{\|}=3.50 \times 10^{-17}, \\
& a_{\perp}=5.25 \times 10^{-17} \mathrm{erg}^{1 / 2} \cdot \mathrm{K} \cdot \mathrm{s}
\end{aligned}
$$

should be used in the case of the phonon scattering; and the integrals $J_{1}^{\prime}, J_{2}^{\prime}$ and the coefficients

$$
\begin{aligned}
& a_{\|}=3.09 \times 10^{-17}, \\
& a_{\perp}=4.67 \times 10^{-17} \mathrm{erg}^{1 / 2} \cdot \mathrm{K} \cdot \mathrm{s}
\end{aligned}
$$

should be used in the case of the mixed scattering.

[1] S. Shevchenko, A. N. Tereshchenko, Solid State Phenom. 156-158, 289 (2009); https://doi.org/10.4028/www. scientific.net/SSP.156-158.289.

[2] Z. Liu, M. O. Nestoklon, J. L. Cheng, E. L. Ivchenko, M. W. Wu, Phys. Solid State 55, 1619 (2013); https: //doi.org/10.1134/S1063783413080167.

[3] S. V. Luniov, O. V. Burban, P. F. Nazarchuk, Semiconductors 49, 574 (2015); https://doi.org/10.1134/ S1063782615050140.

[4] G. P. Gaidar, E. Yu. Gaivoronskaya, Surf. Eng. Appl. Electrochem. 54, 385 (2018); https://doi.org/10.310 3/S1068375518040063.

[5] S. V. Luniov, P. F. Nazarchuk, O. V. Burban, Semiconductors 48, 438 (2014); https://doi.org/10.1134/ S1063782614040198.

[6] G. P. Gaidar, P. I. Baranskii, J. Phys. Stud. 24, 4603 (2019); https://doi.org/10.30970/jps .23.4603.

[7] Yu. A. Osipyan et al., Electronic Properties of Dislocations in Semiconductors (Editorial URSS, Moscow, 2000).

[8] W. Schröter, H. Cerva, Solid State Phenom. 85-86, 67 (2001); https://doi.org/10.4028/www.scientific .net/SSP. 85-86.67.

[9] G. P. Gaidar, A. P. Dolgolenko, P. G. Litovchenko, Probl. Atom. Sci. Technol. No.4(62), 263 (2009).

[10] M. Trempa, G. Müller, J. Friedrich, C. Reimann, in Handbook of Photovoltaic Silicon, edited by D. Yang (Springer, Berlin-Heidelberg, 2019), p. 589; https://do i. org/10.1007/978-3-662-56472-1_25.

[11] C. W. Lan, in Handbook of Photovoltaic Silicon, edited by D. Yang (Springer, Berlin-Heidelberg, 2019), p. 175; https : //doi . org/10.1007/978-3-662-56472-1_34.

[12] M. Kittler, M. Reiche, Adv. Eng. Mater. 11, 249 (2009); https://doi.org/10.1002/adem. 200800283.

[13] P. I. Baranskii, A. E. Belyaev, G. P. Gaidar, Kinetic Effects in Multi-Valley Semiconductors (Naukova Dumka, Kyiv, 2019).

[14] P. I. Baranskii, I. S. Buda, I. V. Dakhovskii, Theory of Thermoelectric and Thermomagnetic Phenomena in Anisotropic Semiconductors (Naukova Dumka, Kiev, 1987).

[15] P. I. Baranskii, I. S. Buda, I. V. Dakhovskii, V. V. Kolomoets, Electrical and Galvanomagnetic Phenomena in Anisotropic Semiconductors (Naukova Dumka, Kiev, 1977).

[16] G. P. Gaidar, P. I. Baranskii, Physica B 441, 80 (2014); https://doi.org/10.1016/j.physb.2014.02.011.

[17] V. M. Babich, N. I. Bletskan, E. F. Venger, Oxygen in Silicon Single Crystals (Interpress LTD, Kyiv, 1997); http://journal-spqeo.org.ua/users/books/0 -in_Si.pdf.

[18] V. E. Bakhrushin, Preparation and Physical Properties of Lightly Doped Layers of Multilayer Compositions (GU "ZIGMU", Zaporizhzhia, 2001).

[19] U. Bardsli, Usp. Fiz. Nauk 73, 121 (1961); https://do i. org/10.3367/UFNr.0073.196101d.0121.

[20] D. Cavalcoli, A. Cavallini, E. Gombia, J. Phys. III France 7, 1399 (1997); https://doi.org/10.1051/jp3: 199719 5. 


\title{
АНІЗОТРОПІЯ РОЗСІЯННЯ ЕЛЕКТРОНІВ У КРЕМНІЇ
}

\author{
Г. П. Гайдар ${ }^{1}$, П. І. Баранський ${ }^{2}$ \\ ${ }^{1}$ Інститут ядерних дослідженъ НАН Украӥни, \\ nросп. Науки, 47, Київ, 03028, Украӥна \\ e-mail: gaydar@kinr.kiev.ua \\ ${ }^{2}$ Інститут фізики напівпровідників ім. В. Є. Лашкаръова НАН Украӥни, \\ просп. Науки, 45, Київ, 03028, Украӥна
}

У монокристалах $n$-Si з питомим опором у діапазоні від 23 до 1180 Ом·см досліджено анізотропію розсіяння носіїв заряду залежно від рівня компенсації домішок. Теоретичні розрахунки проведено в межах теорії анізотропного розсіяння. Виміряно електропровідність, ефект Голла й тензоопір кристалів кремнію, які мають різну різницеву й сумарну концентрацію домішок. Виявлено, що компенсація (принаймні в разі ступеня компенсації, що не перевищує 0.83 , та в разі сумарної концентрації йонізованих домішок не більше $2.76 \cdot 10^{14} \mathrm{~cm}^{-3}$ ) практично не змінює анізотропії розсіяння носіїв заряду. Встановлено, що спостережувані зміни анізотропії розсіяння пов'язані лише зі зміною внеску домішкового розсіяння. Дислокації (особливо впорядковано розташовані дислокації) у кристалах кремнію не тільки відповідають за появу глибоких центрів, але здебільшого визначають анізотропію рухливості носіїв заряду та інших важливих характеристик відповідних кристалів. 3 огляду на це досліджено внутрішньодолинну анізотропію розсіяння носіїв заряду на дислокаціях як розсіювачах у разі фіксованого розташування струму щодо напрямку їх переважної орієнтації. Дислокації (які мали виділену орієнтацію) були введені в кристал $n$-Si методом пластичної деформації вигину за температури $1073 \mathrm{~K}$. Кут між струмом і введеними дислокаціями становив близько $90^{\circ}$. Щільність дислокацій визначали за ямками травлення на площині (111) кристалів кремнію після обробки в селективному травнику. Параметр анізотропії рухливості обчислювали за даними тензоопору, отриманого в експериментах з кристалами, які піддавалися (після їх пластичного деформування) одновісній пружній деформації за умов $\mathbf{X}\|\mathbf{j}\|$ [001] ( $X$ - механічне напруження стиснення, $j$ - струм крізь зразок) за $77 \mathrm{~K}$. Установлено, що в кристалах $n$-Si внутрішньодолинна анізотропія розсіяння на дислокаціях, уведених методом пластичної деформації вигину, значно більша, ніж анізотропія розсіяння на заряджених точкових дефектах.

Ключові слова: кремній, ефект Голла, тензоопір, ступінь компенсації, анізотропія розсіяння, дислокації. 